\title{
OPTIMALISASI FUNGSI INTERMEDIASI PERBANKAN SYARIAH BERBASIS SEKTORAL DI ERA OTONOMI DAERAH
}

\author{
Muh Rudi Nugroho \\ Prodi Ekonomi Syariah FEBI UIN Sunan kalijaga \\ Laksda Adisucipto, Caturtunggal, Kec. Depok, Kabupaten Sleman, Daerah Istimewa \\ Yogyakarta 55281 \\ E-mail Korespondensi: muhrudi82@gmail.com
}

Naskah Diterima: Desember 2015; Disetujui: Maret 2016

\begin{abstract}
This study aims to analyze by simulating the growth of Islamic banking if synergy with state agencies/areas of financial management. In this simulation, third-party funds proxied by $10 \%$ of the provincial budget funds (APBD). Using regression analysis, $10 \%$ of funds allocated APDB implications for the development of the province of Islamic banking, which is measured by the amount of credit distribution. This condition indicates that optimization of the Islamic banking intermediation function can be conducted based sector in the era of regional autonomy, because it has mulplier effect, both on Islamic banking and government. By sector, the nine sector contributed to provincial GDP will increase along with the increase in Islamic banking credit distribution. On the other hand, the increase in deposits will have a positive impact on GDP rising in some sectors. To support the optimization process of Islamic banking intermediation, the Islamic banking should be directed to investment banks, so that Islamic banking and regional development in the era of regional autonomy can be run together. This research is expected to contribute to the financial management of the country/region that has implications for the development of Islamic banking, through the regulation of the Ministry of Finance and Bank Indonesia.
\end{abstract}

Keywords: autonomy, Islamic banking, local government, intermediation, and the investment bank.

JEL Classification: F43, P45

Abstrak: Penelitian ini bertujuan untuk menganalisis dengan mensimulasikan pertumbuhan perbankan syariah jika bersinergi dengan lembaga / bidang manajemen keuangan negara. Dalam simulasi ini, dana pihak ketiga diproklamasikan sebesar $10 \%$ dari dana anggaran provinsi (APBD). Dengan menggunakan analisis regresi, $10 \%$ dana dialokasikan untuk implikasi APDB terhadap perkembangan perbankan syariah, yang diukur dengan jumlah penyaluran kredit. Kondisi ini mengindikasikan bahwa optimalisasi fungsi intermediasi perbankan syariah dapat dilakukan berbasis sektor pada era otonomi daerah, karena memiliki efek mulplier, baik pada perbankan syariah maupun pemerintah. Secara sektoral, sembilan sektor berkontribusi terhadap PDB provinsi akan meningkat seiring dengan meningkatnya penyaluran kredit perbankan syariah. Di sisi lain, kenaikan simpanan akan berdampak positif terhadap kenaikan PDB di beberapa sektor. Untuk menunjang proses optimalisasi intermediasi perbankan syariah, perbankan syariah harus diarahkan ke bank investasi, sehingga perbankan syariah dan pembangunan daerah di era otonomi daerah dapat berjalan bersama. Penelitian ini diharapkan dapat memberikan kontribusi terhadap pengelolaan keuangan negara / kawasan yang berimplikasi pada perkembangan perbankan syariah, melalui peraturan Menteri Keuangan dan Bank Indonesia.

Kata Kunci: otonomi, perbankan syariah, pemerintah daerah, intermediasi, dan bank investasi.

Klasifikasi JEL: F43, P45 


\section{PENDAHULUAN}

Perbankan syariah mengalami pertumbuhan yang cukup signifikan dari tahun ke tahun. Hingga Juni 2015, tercatat sebanyak 12 Bank Umum Syariah (BUS), dengan jumlah jaringan kantor bank mencapai 2,121; 22 Unit Usaha Syariah (UUS), dengan jumlah jaringan kantor bank mencapai 327; serta 161 Bank Pembiayaaan Rakyat Syariah (BPRS), dengan jumlah jaringan kantor bank mencapai 433, sehingga seluruh jaringan kantor pusat, kantor cabang, kantor cabang pembantu, dan kantor kas mencapai 2,881 unit (BI, 2015).

Indikator internal perbankan syariah per Juni 2015 antara lain; Financing to Deposit Ratio (FDR) rata-rata sebesar 96,52\% jauh lebih tinggi dari pada bank konvensional dengan Loan to Deposit Ratio (LDR) rata-rata sebesar $87,3 \%$. Hal ini menunjukkan bahwa fungsi intermediary di bank syariah dapat berjalan lebih baik dari bank konvensional. Untuk risiko kredit macet Non Performing Loan (NPL) atau di dalam bank syariah dinamakan Non Performing Finance $(N P F)$, bank syariah lebih rendah yaitu sebesar $4,73 \%$ sedang bank konvensional sebesar 5,7\%. Hal ini menunjukkan bahwa kredit macet di bank syariah lebih kecil dari pada bank konvensional. ROE perbankan syariah mencapai 7,98\% dan ROA sebesar 0.89\% (BI, 2015).

Aset bank syariah di pertengahan tahun 2015 mampu tumbuh 9\%; pembiayaan bank syariah tumbuh $6,6 \%$ dan penghimpunan dana pihak ketiga bank syariah tumbuh hingga $7,29 \%$. Angka pertumbuhan pada tiga indikator tersebut tergolong melemah dibandingkan pada saat yang sama di tahun 2014, dimana aset tumbuh $13 \%$, pembiayaan tumbuh $8,76 \%$, dan DPK tumbuh 11,41\% (BI, 2015). Perlambatan pertumbuhan perbankan syariah ini sejalan dengan perlambatan perumbuhan ekonomi nasional. Kondisi ini menggambarkan banyaknya tantangan pertumbuhan perbankan syariah Indonesia, sehingga konsep pengembangan berbasis sektoral dimungkinkan menjadi salah satu upaya penguatan pertumbuhan di era otonomi seperti saat ini.

Berkaitan dengan wewenang dalam konteks otonomi daerah, maka daerah otonom berhak mengurus urusan pemerintahanya yang tertulis pada Pasal 12 UU No 32 Tahun 2004.

Presiden selaku Kepala Pemerintahan memegang kekuasaan atas pengelolaan keuangan negara. Presiden berfungsi sebagai Chief Executive Officer (CEO) dan Menteri Keuangan berperan dan berfungsi sebagai Chief Financial Officer (CFO) sedangkan menteri/pimpinan lembaga berperan sebagai Chief Operating Officers (COO). Hubungan tersebut tergambar pada lampiran 1.

Kementerian Keuangan bertanggungjawab untuk mengelola pendapatan Negara, pengeluaran negara dan aset negara melalui pengelolaan APBN. Pada tahun 2013 APBN di atas Rp 1.600 triliun, naik dua kali lipat dalam lima tahun terakhir. Angka tersebut akan semakin membesar karena ekonomi Indonesia tumbuh dengan amat baik, bahkan diramalkan banyak pengamat pada tahun 2030, Indonesia akan menjadi ekonomi terbesar ke-6 di dunia. Perjalanan bangsa kita 15-20 tahun lagi akan sangat krusial untuk menentukan langkah Indonesia untuk menjadi negara maju yang berpendapatan tinggi dan berkeadilan sosial.

Momen ini membawa peluang pada perkembangan perbankan syariah, di mana Bank Indonesia sudah memfasilitasi dengan kerangka dual-banking system. Hal ini berarti sistem perbankan syariah dan perbankan konvensional secara sinergis mendukung mobilisasi dana masyarakat secara lebih luas untuk meningkatkan kemampuan pembiayaan bagi sektor-sektor perekonomian nasional. Mekanisme dapat direlisasikan dengan penyimpanan dana APBN/APBD di perbankan syariah, mengingat bahwa selama ini pengelolaan APBN/APBD full conventional banking.

Dari pemaparan di atas, guna merespon 
perkembangan industri keuangan perbankan di era otonomi daerah, maka penelitian ini akan menganalisis dan mensimulasikan bagaimana pertumbuhan perbankan syariah jika terdapat sinergi antara perbankan syariah dengan lembaga-lembaga negara/daerah dalam pengelolaan keuangan negara/daerah. Penelitian ini diharapkan dapat berkontribusi terhadap pengelolaan keuangan negara/ daerah yang berimplikasi pada perkembangan perbankan syariah, melalui regulasi.

\section{METODE PENELITIAN}

Penelitian menggunakan data panel dalam tahunan kurun waktu tahun 2006 sampai dengan 2011 dari Statistik Perbankan Syariah yang diterbitkan oleh Bank Indonesia dan Laporan Realisasi APBD provinsi. Provinsi yang menjadi sampel dalam penelitian ini adalah provinsi yang di dalamnya sudah berdiri Bank Pembangunan Daerah (BPD) Syariah, dan terdapat sebanyak 15 provinsi sehingga jumlah observasinya 45 .

\section{Spesifikasi model}

Spesifikasi model yang digunakan dalam penelitian ini adalah sebagai berikut:

\section{Model 1}

$$
\begin{aligned}
\Delta P_{j, t}=S W B I_{j, t} & +\Delta D P K_{j, t}+\Delta J B_{j, t}+S_{1_{j, t}}+S_{2 j, t} \\
& +S_{3 j, t}+S_{4 j, t}+S_{5_{j, t}}+S_{6 j, t} \\
& +S_{7 j, t}+S_{8_{j, t}}+S_{9_{j, t}}+\varepsilon
\end{aligned}
$$

\section{Model 2}

$$
\begin{aligned}
& \triangle P D R B_{i, j, t}=S W B I_{j, t}+\Delta D P K_{j, t}+\Delta J B_{j, t}+\Delta P_{j, t} \\
& +\varepsilon
\end{aligned}
$$

di mana

P : Penyaluran pembiayaan di perbankan syariah (juta rupiah)

PDRB : Produk Domestik Regional Bruto (juta rupiah)

SWBI : Sertifikat Wadian Bank Indonesia (juta rupiah)

DPK : DPK diproksikan 10\% dari total APBD Provinsi (juta rupiah)

JB : Jumlah BPD Syariah, termasuk Kantor
Kas dan Office Channeling (unit)

S1 : PDRB Provinsi Sektor Pertanian (juta rupiah)

S2 : PDRB Provinsi Sektor Pertambangan dan penggalian (juta rupiah)

S3 : PDRB Provinsi Sektor Industri pengolahan (juta rupiah)

S4 : PDRB Provinsi Sektor Listrik, gas dan air bersih (juta rupiah)

S5 : PDRB Provinsi Sektor Konstruksi (juta rupiah)

S6 : PDRB Provinsi Sektor Perdagangan, hotel \& restoran (juta rupiah)

S7 : PDRB Provinsi Sektor Pengangkutan dan komunikasi (juta rupiah)

S8 : PDRB Provinsi sektor keuangan, persewaan \& jasa perusahaan (juta Rupiah)

S9 : PDRB Provinsi Sektor Jasa-jasa (juta rupiah)

i : sektor/ lapangan USAHA (S1, S2, S3, S4, S5, S5, S7, S8, S9)

j : provinsi

t : periode

\section{Regresi linier dengan data panel}

Verbeek (2012: 310) mengemukakan bahwa keuntungan regresi dengan data panel adalah kemampuann regresi data panel dalam mengidentifikasi parameter-parameter regresi secara pasti tanpa membutuhkan asumsi restriksi atau kendala. Menurut Baltagi (2005), keunggulan penggunaan data panel dibanding data runtun waktu dan data lintas sektoral adalah:

Estimasi data panel dapat menunjukkan adanya heterogenitas dalam tiap unit;

Dengan data panel, data lebih informatif, mengurangi kolinieritas antara variabel, meningkatkan derajat kebebasan dan lebih efisien;

Data panel cocok untuk menggambarkan adanya dinamika perubahan;

Data panel dapat lebih mampu mendeteksi dan mengukur dampak; 
Data panel bisa digunakan untuk studi dengan model yang lebih lengkap;

Data panel dapat meminimumkan bias yang mungkin dihasilkan dalam agregasi.

Estimasi model regresi penggabungan semua data untuk intersep dan koefisien slope konstan setiap waktu dan unit biasa disebut juga dengan estimasi regresi data panel dengan metode Pooled Least Square, yang mempunyai bentuk spesifikasi sebagai berikut:

$Y_{i t}=\beta_{1}+\beta_{2} X_{2 i t}+\beta_{3} X_{3 i t}+\mu_{i t}$

Jika model regresi diasumsikan mempunyai koefisien slope konstan tetapi intersep bervariasi tiap unit maka digunakan variabel dummy waktu dan unit.

$Y_{i t}=\beta_{1 t}+\beta_{2} X_{2 i t}+\beta_{3} X_{3 i t}+\mu_{i t}$

Model (2) ini dikenal dengan Fixed Effect Model (FEM). Intersep meskipun bervariasi tiap unit tapi tidak berbeda dalam tiap waktu (time invariant). Variabel dummy digunakan untuk mengetahui besarnya perbedaan koefisien tiap unit (differential intercept dummies) dan model dapat dituliskan sebagai berikut:

$Y_{i t}=\alpha_{1}+\alpha_{2} D_{2 i}+\alpha_{3} D_{3 i}+\alpha_{4} D_{4 i}+$

$\beta_{2 i t} X_{2 i t}+\beta_{3} X_{3 i t}+\mu_{i t}$

Model (2) ini dikenal juga sebagai Covariance Model. Salah satu alasan digunakannya fixed effect model adalah karena, kesimpulan (inferensi) yang akan diambil dari model yang akan diteliti hanya akan mempertimbangkan efeknnya pada sampel yang ada dan bukan pada populasi. Hal ini berlainan dengan tujuan dipakainya random effect model, yaitu untuk melihat efeknya pada populasi dalam mengambil kesimpulan (Verbeek, 2012).

Model estimasi regresi data panel yang ketiga adalah error component model atau disebut juga Random Effect Model (REM). Model REM ini melibatkan korelasi antar error term karena berubahnya waktu maupun karena berbedanya unit observasi. Model dasarnya dapat diformulasikan sebagai berikut:

$Y_{i t}=\beta_{1 t}+\beta_{2} X_{2 i t}+\beta_{3} X_{3 i t}+\mu_{i t}$

Ketiga model tersebut akan berbeda dalam intrepetasi analisisnya sehingga perlu dilakukan pemilihan model untuk memperoleh estimasi yang efisien sesuai dengan penggunaan regresi data panel.

\section{Uji statistik F}

Uji statistik F digunakan untuk memilih antara metode PLS tanpa variabel dummy atau memilih fixed effect. Uji statistik F yang dapat dilakukan adalah sebagai berikut (Verbeek, 2012):

$$
F(n-1, n T-n-K)=\frac{\left(R_{U R}^{2}-R_{R}^{2}\right) /(n-1)}{\left(1-R_{U R}^{2}\right) /(n T-n-K)}
$$

Di mana,

$\mathrm{R}^{2} \mathrm{UR} \quad$ : mengacu pada unrestricted model

$\mathrm{R}^{2} \mathrm{R} \quad$ : mengacu pada restricted model

$n \quad$ : jumlah unit cross section

$T \quad$ : jumlah unit waktu

$K$ : jumlah parameter yang akan diestimasi

Jika ternyata hasil perhitungan $\mathrm{F}$ stat $\geq \mathrm{F}$ $(n-1, n T-n-K)$, berarti Ho ditolak, artinya intersep untuk semua cross section tidak sama. Dalam hal ini, FEM digunakan untuk mengestimasi persamaan regresi. Sementara itu, hal-hal yang harus diperhatikan jika menggunakan FEM (Verbeek, 2012). Pertama, penggunaan variabel dummy akan menimbulkan masalah degrees of freedom. Kedua, kemungkinan terjadi multikolienaritas. Ketiga, FEM tidak bisa digunakan untuk mengetahui dampak variabel yang invariant (misal, jenis kelamin, ras, dll). Keempat, error term harus diperhatikan sehingga asumsi klasik error term harus dimodifikasi. 


\section{Uji lagrange multiplier}

Uji Lagrange Multiplier (LM) digunakan untuk memilih antara OLS tanpa variabel dummy atau memilih random effect. Uji Lagrange Multiplier (LM) yang dapat dilakukan adalah (Verbeek, 2012):

$$
L M=\frac{n T}{2(T-1)}\left(\frac{\sum_{i=1}^{n}\left(\sum_{i=1}^{n} e_{i t}\right)}{\sum_{i=1}^{n} \sum_{i=1}^{n} e_{i t}^{2}}-1\right)^{2}
$$

Di mana,

n : jumlah individu

$T \quad$ : jumlah periode waktu

$e \quad$ : residual metode OLS

Jika perhitungan $L M>X^{2}$ dengan satu derajat kebebasan, maka Ho ditolak, artinya REM bisa digunakan untuk mengestimasi persamaan regresi.

\section{Uji Haussman}

Uji Haussman digunakan untuk memilih antara Fixed Effect Model (FEM) atau Random Effect Model (REM). Hipotesis dari uji Hausman Gujarati, 2003) adalah:

\section{$H_{0}$ : estimator random konsisten \\ $H_{a}$ : estimator random tidak konsisten}

Di mana Ho diterima artinya REM lebih baik digunakan daripada FEM, dan sebaliknya. Maka $H_{o}$ diterima/ ditolak jika:

$$
\begin{array}{ll}
X^{2}{ }_{\text {tab }}>X^{2}{ }_{\text {hit }} & : H_{o} \text { diterima } \\
X^{2}{ }_{\text {tab }}<X^{2}{ }_{\text {hit }} & : H_{0} \text { ditolak }
\end{array}
$$

Untuk mendapatkan nilai $X^{2}{ }_{\text {hit }}$ diambil dari perbedaan nilai beta dan covarian setiap metode. Uji statistik Hausman yang dapat dilakukan adalah:

$$
W=\frac{\left(\overline{\boldsymbol{\beta}}_{F E M}-\overline{\boldsymbol{\beta}}_{R E M}\right)^{2}}{\left(V\left(\overline{\boldsymbol{\beta}}_{F E M}\right)-V\left(\overline{\boldsymbol{\beta}}_{R E M}\right)\right)} \sim X^{2}(\mathbf{1})
$$

dan untuk multivariate,

$\boldsymbol{W}=$

$\left(\overline{\boldsymbol{\beta}}_{\text {FEM }}-\right.$

$$
\begin{aligned}
& \left.\bar{\beta}_{R E M}\right)\left(V\left(\bar{\beta}_{F E M}\right)-V\left(\bar{\beta}_{R E M}\right)\right)^{-1}\left(\bar{\beta}_{F E M}-\right. \\
& \left.\bar{\beta}_{R E M}\right) \sim X^{2}(k)
\end{aligned}
$$

Uji statistik Haussman ini mengikuti distribusi chi-square $\left(X^{2}\right)$ dengan degrees of freedom sebanyak $k$ dimana $k$ adalah jumlah variabel independen. Jika nilai statistik Haussman lebih besar dari nilai kritisnya maka model yang tepat adalah FEM, sedangkan sebaliknya bila nilai statistik Haussman lebih kecil dari nilai kritisnya maka model yang tepat adalah REM. Menurut Judge (1985), ada beberapa hal yang harus diperhatikan untuk menentukan pendekatan mana yang dipilih (FEM atau REM) dalam estimasi panel data, yaitu: Jika $\varepsilon$ dan $X$ berkorelasi, maka lebih baik menggunakan $F E M$, dan jika $\varepsilon$ dan $X$ tidak berkorelasi, maka lebih baik digunakan REM, Jika $T$ (jumlah time series) besar dan $n$ (jumlah individu/ unit) kecil, perbedaan keduanya relatif kecil, maka lebih baik menggunakan FEM, Jika $n$ besar dan $T$ kecil, digunakan FEM apabila unit tidak random dari sampel yang besar dan digunakan REM apabila unit diambil secara random dan Jika $n$ besar dan $T$ kecil dan apabila asumsi REM terpenuhi, estimator REM lebih efisien dibandingkan FEM.

\section{HASIL DAN PEMBAHASAN}

\section{Analisis model 1}

Hasil analisis regresi model 1 sebagaimana dalam lampiran 2, secara umum model tersebut fit, yang ditunjukkan dengan $\mathrm{R}^{2}=97.99 \%$ dan $\mathrm{F}$ statistik 130.28 (prob 0.0000), serta konstanta (c) yang tidak signifikan (t-Statistik 1.2 dan probability 0.24). Dana Pihak Ketiga (DPK) diproksikan dengan 10\% dari total ABPD Provinsi. Asumsinya, penempatan dana APBD di perbankan syariah, akan berimplikasi pada perkembangan perbankan syariah yang digambarkan dengan jumlah penyaluran pembiayaan.

Dalam konteks ini variabel SWBI, DPK, 
dan jumlah bank tidak berpengaruh signifikan terhadap pembiayaan di perbankan syariah. PDRB berdasarkan sektor. Lapangan usaha juga berkontribusi terhadap pembiayaan di perbankan syariah.

Dari sembilan sektor penyumbang PDRB provinsi, sektor pengangkutan dan komunikasi yang paling berpengaruh terhadap pembiayaan di perbankan syariah. Setiap kenaikan jumlah PDRB di sektor pengangkutan dan komunikasi sebesar satu juta rupiah, maka pembiayaan di perbankan syariah akan naik sebesar Rp 5,49 juta. Secara statistik, hubungan ini signifikan dengan a 1\% (t-statistik 5,98 dan probability $0,0000)$. Meskipun sektor ini sudah optimal, perlu optimalisasi pembiayaan agar lebih efisien.

Untuk sektor industri pengolahan, setiap terjadi kenaikan PDRB di sektor industri pengolahan satu juta rupiah, akan berimplikasi pada kenaikan pembiayaan di perbankan syariah sebesar Rp 0,15 juta. Secara statistik, hubungan ini signifikan dengan a 5\% (tstatistik 3,23 dan probability 0,0029). Kenaikan PDRB di sektor industri pengolahan dan kenaikan pembiayaan di perbankan syariah perbandingannya tidak sepadan, hanya $7: 1$, maka dari itu perlu optimalisasi pembiayaan di sektor industri pengolahan agar lebih efisien.

Di sisi lain, PDRB di sektor keuangan, persewaan \& jasa perusahaan dan pembiayaan di perbankan syariah memiliki perbandingan yang cukup tinggi, yaitu $1: 6$. Setiap terjadi kenaikan PDRB di sektor keuangan, persewaan \& jasa perusahaan maka pembiayaan di perbankan syariah akan naik sebesar Rp 5,61 juta. Hubungan ini signifikan dengan a 10\% (tstatistik 1,31 dan probability 0,1042).

Beberapa sektor ekonomi memiliki hubungan negatif terhadap pembiayaan di perbankan syariah. Artinya setiap terjadi kenaikan PDRB di sektor-sektor tersebut, justru akan menurunkan pembiayaan di perbankan syariah. Di antara sektor yang berhubungan negatif tersebut adalah sektor pertanian, sektor perdagangan, hotel \& restoran, serta sektor jasa-jasa.

Pada sektor pertanian, setiap terjadi kenaikan PDRB sebesar satu juta rupiah, maka pembiayaan di perbankan syariah akan turun hingga Rp 2,03 juta. Hubungan ini signifikan dengan a $1 \%$ (t-statistik -3.68 dan probability 0,0008). Sama halnya dengan sektor pertanian, sektor perdagangan, hotel \& restoran setiap kenaikan PDRB sebesar satu juta rupiah, akan berdampak pada penurunan pembiayaan di perbankan syariah sebesar $\mathrm{Rp} 0,54$ juta. Hubungan ini signifikan dengan a $1 \%$ (t-statistik -3,27 dan probability 0,0025).

Sektor jasa-jasa juga berhubungan negatif dengan pembiayaan di perbankan syariah, meskipun hubungan tersebut tidak signifikan secara statistik. Beberapa sektor ekonomi yang berhubungan negatif terhadap pembiayaan di perbankan syariah tersebut mengindikasikan ketidakefisienan, maka dari itu perlu optimalisasi pembiayaan di sektor-sektor tersebut agar menjadi efisien. Hal ini tidak menutup kemungkinan untuk melakukan optimalisasi pembiayaan di sektor-sektor yang sudah efisien, dengan tujuan agar sektor-sektor tersebut lebih efisien dan efektif. Dengan kata lain kondisi ini mengindikasikan optimalisasi fungsi intermediasi perbankan syariah berbasis otonomi daerah, yang mempunyai multiplier effect baik pada perbankan syariah maupun pada Pemda. Salah satu dampak yang riel adalah pertumbuhan sektor riel di tiap daerah, yang secara tidak langsung juga akan berdampak pada pertumbuhan ekonomi nasional.

\section{Analisis model 2}

\section{Sektor pertanian (S1)}

$$
\begin{aligned}
\mathrm{S} 1= & 13331990+3,38 \mathrm{P}+11,19 \mathrm{SWBI}+3,76 \mathrm{DPK} \\
& (0,99) \quad(2,77)^{* *} \quad(3,34)^{* *} \quad(3,44)^{* *} \\
& +18547,45 \mathrm{JB} \\
& (0,48)^{* *}
\end{aligned}
$$




$$
\mathrm{R}^{2}=0,99 \quad \mathrm{~F}=104
$$

PDRB di sektor pertanian akan meningkat dengan adanya alokasi dana APBD sebesar 10\% di perbankan syariah. Jika penyaluran pembiayaan perbankan syariah di sektor pertanian naik satu juta rupiah, maka PDRB sektor pertanian akan naik sebesar Rp 3,38 juta. Adanya kenaikan DPK perbankan syariah sebesar satu juta rupiah, akan berimplikasi pada peningkatan PDRB sektor pertanian sebesar Rp 3,76 juta. Jika satu bank syariah baru berdiri dan beroperasi, maka PDRB sektor pertanian di wilayah pendirian bank tersebut akan naik sebesar Rp 18.547,45 juta.

\section{Sektor pertambangan dan penggalian (S2)}

$$
\begin{aligned}
& \mathrm{S} 2=7766757+0,28 \mathrm{P}+9,83 \mathrm{SWBI}+2,55 \mathrm{DPK} \\
& (1,39) \quad(1,23)^{*} \quad(2,91)^{* *} \quad(2,32)^{* *} \\
& +93736,63 \mathrm{JB} \\
& (2,42)^{* *} \\
& \mathrm{R}^{2}=0,99 \quad \mathrm{~F}=100
\end{aligned}
$$

PDRB di sektor pertambangan dan penggalian akan meningkat dengan adanya alokasi dana APBD sebesar $10 \%$ di perbankan syariah. Jika penyaluran pembiayaan perbankan syariah di sektor pertambangan dan penggalian naik satu juta rupiah, maka PDRB sektor pertambangan dan penggalian akan naik sebesar Rp 1.23 juta. Adanya kenaikan DPK perbankan syariah sebesar satu juta rupiah, akan berimplikasi pada peningkatan PDRB sektor pertambangan dan penggalian sebesar Rp 2.55 juta. Jika satu bank syariah baru berdiri dan beroperasi, maka PDRB sektor pertambangan dan penggalian di wilayah pendirian bank tersebut akan naik sebesar Rp 93,736.63 juta.

\section{Sektor industri pengolahan (S3)}

$$
\begin{aligned}
\mathrm{S} 3= & 26375260+0.28 \mathrm{P}+9.83 \mathrm{SWBI}+2.57 \mathrm{DPK} \\
& (2.08)^{* * *}(0.35) \quad(-0.51) \quad(1.83)^{* *} \\
& +7996.836 \mathrm{JB}
\end{aligned}
$$

$$
\mathrm{R}^{2}=0.99 \quad \mathrm{~F}=22
$$

Dari empat variabel yang dipilih, hanyak variabel DPK yang signifikan berpengaruh terhadap PDRB di sektor industri pengolahan $(\alpha=5 \%)$. Setiap terjadi kenaikan DPK di perbankan syariah sebesar satu juta rupiah, maka terhadap PDRB di sektor industri pengolahan akan meningkat sebesar $\mathrm{Rp} 2,57$ juta.

Sektor listrik, gas dan air bersih (S4)

$\mathrm{S} 4=1145928+0,57 \mathrm{P}+2,46 \mathrm{SWBI}-0,61 \mathrm{DPK}+$ 3926,98JB

$$
\begin{gathered}
(7,83)^{* * *}(2,38)^{* *}(3,71)^{* * *}(-2,82)^{* *} \quad(1,526)^{*} \\
\mathrm{R}^{2}=0,99 \quad \mathrm{~F}=452
\end{gathered}
$$

Pada sektor listrik, gas dan air bersih, tiap terjadi kenaikan pembiayaan di perbankan syariah sebesar satu juta rupiah, maka PDRB sektor listrik, gas dan air bersih akan naik sebesar Rp 0,57 juta. Jika ada penambahan unit bank, maka tiap kenaikan satu unit bank, akan berdampak pada peningkatan PDRB sektor listrik, gas dan air bersih sebesar Rp 3.926,98 juta. Sedangkan DPK berhubungan terbalik, yang mana setiap terjadi kenaikan DPK di perbankan syariah sebesar satu juta rupiah, justru PDRB sektor listrik, gas dan air bersih akan menurun hingga $\mathrm{Rp} 0,61$ juta.

\section{Sektor konstruksi (S5)}

$$
\begin{aligned}
& \mathrm{S} 5=5000294+0,89 \mathrm{P}+4,05 \mathrm{SWBI}-0,69 \mathrm{DPK} \\
& (6,57)^{* * *}(2,72)^{* *} \quad(1,17) \\
& +49055,85 \mathrm{JB} \\
& (1,54)^{*} \\
& \mathrm{R}^{2}=0,99 \quad \mathrm{~F}=401
\end{aligned}
$$

Pada sektor pembiayaan dan jumlah bank berpengaruh signifikan terhadap PDRB sektor konstruksi. Setiap kenaikan per satu juta rupiah pembiayaan perbankan syariah, maka PDRB 
sektor pertanian akan naik sebesar Rp 0,89 juta, sedangkan jumlah bank, tiap kenaikan satu unit akan berdampak pada peningkatan jumlah PDRB sektor konstruksi hingga Rp 49.055,85 juta.

Sektor perdagangan, hotel \& restoran (S6)

$$
\begin{aligned}
\text { S6 }= & 20072457+5,37 \mathrm{P}+21,23 \mathrm{SWBI}-3,58 \mathrm{DPK} \\
& (6,87)^{* * *}(1,55)^{*} \quad(1,60) \quad(-0,83) \\
& +49779,39 \mathrm{JB} \\
& (2.33)^{* *} \\
& \mathrm{R}^{2}=0,99 \quad \mathrm{~F}=301
\end{aligned}
$$

Sama halnya dengan PDRB sektor konstruksi, PDRB sektor perdagangan, hotel \& restoran akan mengalami kenaikan sebesar Rp 5,37 juta jika pembiayaan perbankan syariah naik sebesar satu juta rupiah. Demikian juga dengan jumlah bank, kenaikan per unit bank akan meningkatkan PDRB sektor perdagangan, hotel \& restoran sebesar Rp 49.779,39 juta.

\section{Sektor pengangkutan dan komunikasi (S7)}

$$
\begin{aligned}
& \text { S7 }=5176696+1,58 \mathrm{P}+4,53 \mathrm{SWBI}-0,73 \mathrm{DPK} \\
& (2,91)^{* * *}(0,55)^{*} \quad(0,57) \quad(-0,27) \\
& +101394,5 \mathrm{JB} \\
& (1,09)^{*} \\
& R^{2}=0,98 \quad F=93
\end{aligned}
$$

PDRB sektor pengangkutan dan komunikasi akan naik hingga $\mathrm{Rp} 1,58$ juta ketika pembiayaan perbankan syariah naik satu juta rupiah. PDRB sektor pengangkutan dan komunikasi juga akan meningkat sebesar Rp 101.394,5 juta setiap ada penambahan satu unit bank syariah di wilayah tersebut.

\section{Sektor keuangan, persewaan \& jasa perusahaan (S8)}

$$
\begin{aligned}
& \mathrm{S} 7=1352310+5,76 \mathrm{P}+2,89 \mathrm{SWBI}+4,61 \mathrm{DPK} \\
& (7,11)^{* * *}(1,68)^{*} \quad(0,18) \quad(1,87)^{*} \\
& +357732 \mathrm{JB} \\
& (0,81)^{*} \\
& R^{2}=0.99 \quad F=43
\end{aligned}
$$

PDRB sektor keuangan, persewaan \& jasa perusahaan di suatu daerah akan meningkat sebesar Rp 5,76 juta jika terjadi kenaikan pembiayaan perbankan syariah sebesar satu juta rupiah. PDRB sektor tersebut juga akan mengalani peningkatan hingga $\mathrm{Rp}$ 4,61 juta ketika ada kenaikan DPK perbankan syariah satu juta rupiah. Jumlah unit bank syariah juga mempangaruhi PDRB sektor keuangan, persewaan \& jasa perusahaan. PDRB akan naik Rp 357.732 juta jika ada satu unit bank syariah berdiri.

\section{Sektor jasa-jasa (S9)}

$$
\begin{aligned}
& S 9=1414353+4,67 P+2,72 S W B I+5,69 D P K \\
& (67,48)^{* * *}(1,62)^{*}(0,65) \quad(2,02)^{*} \\
& +19512 J B \\
& (1,64)^{*} \\
& R^{2}=0,99 \quad F=68
\end{aligned}
$$

PDRB sektor jasa-jasa akan naik Rp 4,67 juta ketika pembiayaan perbankan syariah naik satu juta rupiah. PDRB sektor tersebut juga akan naik Rp 5,69 juta jika DPK perbankan syariah naik satu juta rupiah. Jika berdiri satu unit bank syariah di suatu wilayah, maka PDRB sektor jasa di wilayah tersebut akan naik Rp 19,512 juta.

\section{SIMPULAN DAN SARAN}

\section{Simpulan}

Hasil penelitian menunjukkan bahwa alokasi $10 \%$ dana APDB provinsi akan berimplikasi pada perkembangan perbankan syariah, yang dalam hal ini diukur dengan besarnya penyaluran pembiayaan perbankan syariah. Kondisi ini menunjukkan bahwa optimalisasi fungsi intermediasi perbankan syariah dapat dilakukan berbasis otonomi daerah, karena mempunyai mulplier effect baik pada perbankan syariah maupun pada Pemda. Salah satu bentuk multiplier effect yaitu pertumbuhan sektor riel di tiap daerah, yang secara tidak langsung juga akan berdampak 
pada pertumbuhan ekonomi nasional. Bukti lain yang memperkuat hal ini adalah Financing to Deposit Ratio (FDR) perbankan syariah $>95 \%$, yang menunjukkan fungsi intermediasi perbankan syariah berjalan dengan baik.

Secara sektoral, sembilan sektor penyumbang PDRB provinsi akan meningkat seiring dengan peningkatan penyaluran pembiayaan perbankan syariah. Di sisi lain, kenaikan DPK akan berdampak positif terhadap kenaikan PDRB beberapa sektor, di antaranya sektor pertanian, sektor pertambangan dan penggalian, sektor industri pengolahan, sektor keuangan, persewaan \& jasa perusahaan, serta sektor jasa-jasa. Penambahan unit bank di suatu wilayah, akan meningkatkan PDRB semua sektor. Temuan ini memperjelas pernyataan sebelumnya, terkait dengan perlunya optimalisasi fungsi intermediasi perbankan syariah berbasis otonomi daerah, dalam rangka pengembangan perbankan syariah di Indonesia.

Untuk mendukung proses optimalisasi fungsi intermediasi perbankan syariah, maka jumlah jaringan perbankan syariah harus ditambah, serta diarahkan menjadi investment bank dalam jangka panjang. Dengan demikian perkembangan perbankan syariah dan pembangunan daerah di era otonomi daerah dapat berjalan bersama, dalam rangka mencapai tujuan pembangunan nasional.

\section{Saran}

Sampel perbankan syariah dalam penelitian ini hanya menggunakan data-data Bank Pembangunan Daerah (BPD) Syariah sebagai proksi dari perbankan syariah, sehingga provinsi yang dimasukkan dalam sampel hanya provinsi yang mempunyai BPD Syariah di wilayahnya. Hal ini dikarenakan keterbatasan data perbankan syariah per provinsi. Oleh karena itu, untuk penelitian selanjutnya dapat menggunakan perbankan syariah secara nasional agar hasil yang diperoleh lebih relevan dalam menggambarkan pola optimalisasi fungsi intermediasi perbankan syariah berbasis otonomi daerah.

\section{DAFTAR PUSTAKA}

Baltagi, B, H, 2005, Econometric Analysis of Panel Data, New York: John Wiley and Sons

Gujarati, Damodar, N. 2003, Basic Econometrics. $4^{\text {th }}$ Ed.New York: The McGraw-Hill Companies, Inc.

Judge, George G, 1985, The Theory and Practice of Econometrics, New York: Wiley

Statistik Perbankan Indonesia Juni 2015, Bank Indonesia

Statistik Perbankan Syariah Juni 2015, Bank Indonesia

Verbeek, Marno, 2012, A Guide to Modern Econometrics, New York: Wiley 